\title{
Paroxysmal Supraventricular Tachycardia and Atrial Fibrillation in the Same Patient: What Seems to be the Link?
}

\author{
Lateef Fatimah ${ }^{1-3 *}$ \\ ${ }^{1}$ Department of Emergency Medicine, Singapore General Hospital, Singapore \\ ${ }^{2}$ Yong Loo Lin School of Medicine, National University of Singapore \\ ${ }^{3}$ Lee Kong Chian Medical School, Nanyang Technological University and Duke NUS Graduate Medical School, Singapore \\ *Corresponding author: Lateef Fatimah, Department of Emergency Medicine, Singapore General Hospital, Singapore
}

\section{ARTICLE INFO}

Received: 幽 July 08, 2021

Published: 幽 July 19, 2021

Citation: Lateef Fatimah. Paroxysmal Supraventricular Tachycardia and Atrial Fibrillation in the Same Patient: What Seems to be the Link?. Biomed J Sci \& Tech Res 37(2)-2021. BJSTR. MS.ID.005982.

\begin{abstract}
In your clinical practice, have you ever come across a patient with Paroxysmal Supraventricular Tachycardia (PSVT), who also occasionally has attacks of paroxysmal atrial fibrillation (AF), or encountered a patient with PSVT that degenerates into AF? These scenarios are not uncommon. There have been cases as well as reports of these in the literature. The prevalence of these two rhythms or their co-existence have intrigued many clinicians and scientists. To date, there have been some postulations as to the possible mechanisms and pathogenesis involved. This paper discusses in a simplified fashion, what some of these possible mechanisms are, as well as the micropathophysiology that may be taking place as clinicians observe these rhythm changes and development.
\end{abstract}

Keywords: Paroxysmal Supraventricular Tachycardia; Atrial Fibrillation; Atrioventricular Nodal Reentrant Tachycardia; Pulmonary Vein

\section{Introduction}

Imagine that you are the emergency physician on duty and a 56-year-old patient, with no past medical problems, presents with palpitations. It has been ongoing the last hour and the patient feels slightly light-headed but had not experienced any episodes of fainting. The nurse performs the 12-lead electrocardiogram (ECG) and shows it to you (Figure 1). You make the diagnosis of Paroxysmal Supraventricular Tachycardia (PSVT) and go on to take a rapid history from the patient, as your resident inserts a large bore cannula and collect some blood for investigations. As you instruct your nurse to prepare the drug Adenosine to be administered to the patient, your resident glance at the cardiac monitor and alert you that the rhythm has changed. He commented that the patient's pulse is irregularly irregular now. The Blood Pressure was 162/ 89.

Your nurse repeats the 12 lead ECG (Figure 2). It has indeed converted to Atrial Fibrillation (AF). You update your nurse that you will not be needing the Adenosine any further in view of the change in rhythm. As you have never encountered such a case before, you wonder what the underlying etiology and mechanism of both PSVT and AF is occurring in the same patient, within such a short span of time.

\section{Supraventricular Tachycardia (SVT)}

SVT is a tachyarrhthmia with its origin above the Bundle of His. It can be divided into three broad groups: PSVT, AF and multifocal atrial tachycardia (MAT). $60 \%$ of the PSVT is atrio-ventricular nodal re-entrant tachycardia (AVNRT), 30\% atrio-ventricular reciprocating tachycardia and $10 \%$ are atrial tachycardia in nature (Figure 3). As it is, AF and atrial flutter are also classified as SVT [1-4]. Therefore, with reference to our case above, is it possible for a patient to have an inter-change of rhythms or a conversion of rhythms from PSVT to AF (both being different forms of SVT)? If this is the case, then what will be the mechanism involved? 


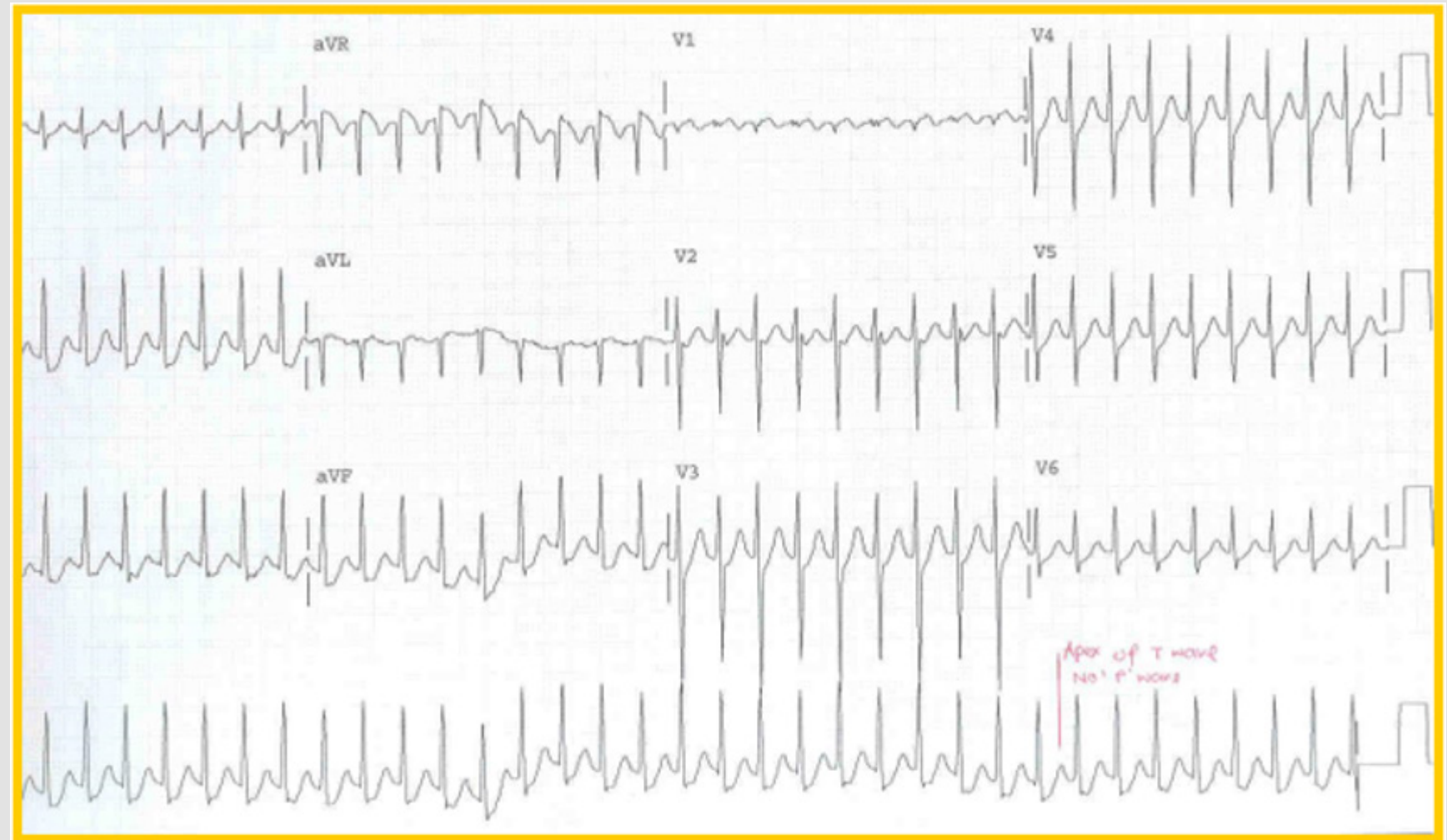

Figure 1: First ECG at presentation showing PSVT.

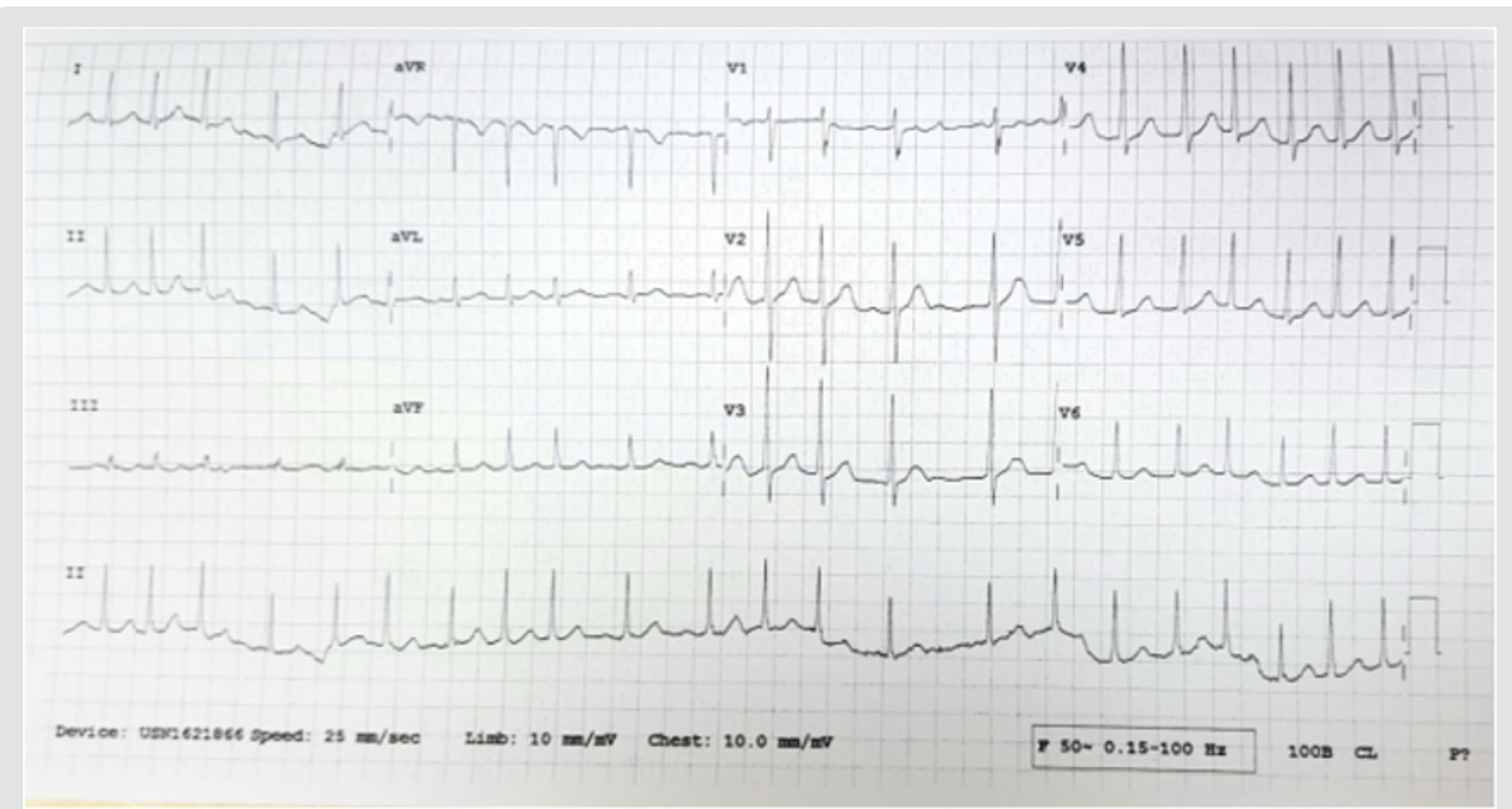

Figure 2: The second 12 lead ECG for the patient showing Atrial Fibrillation. 


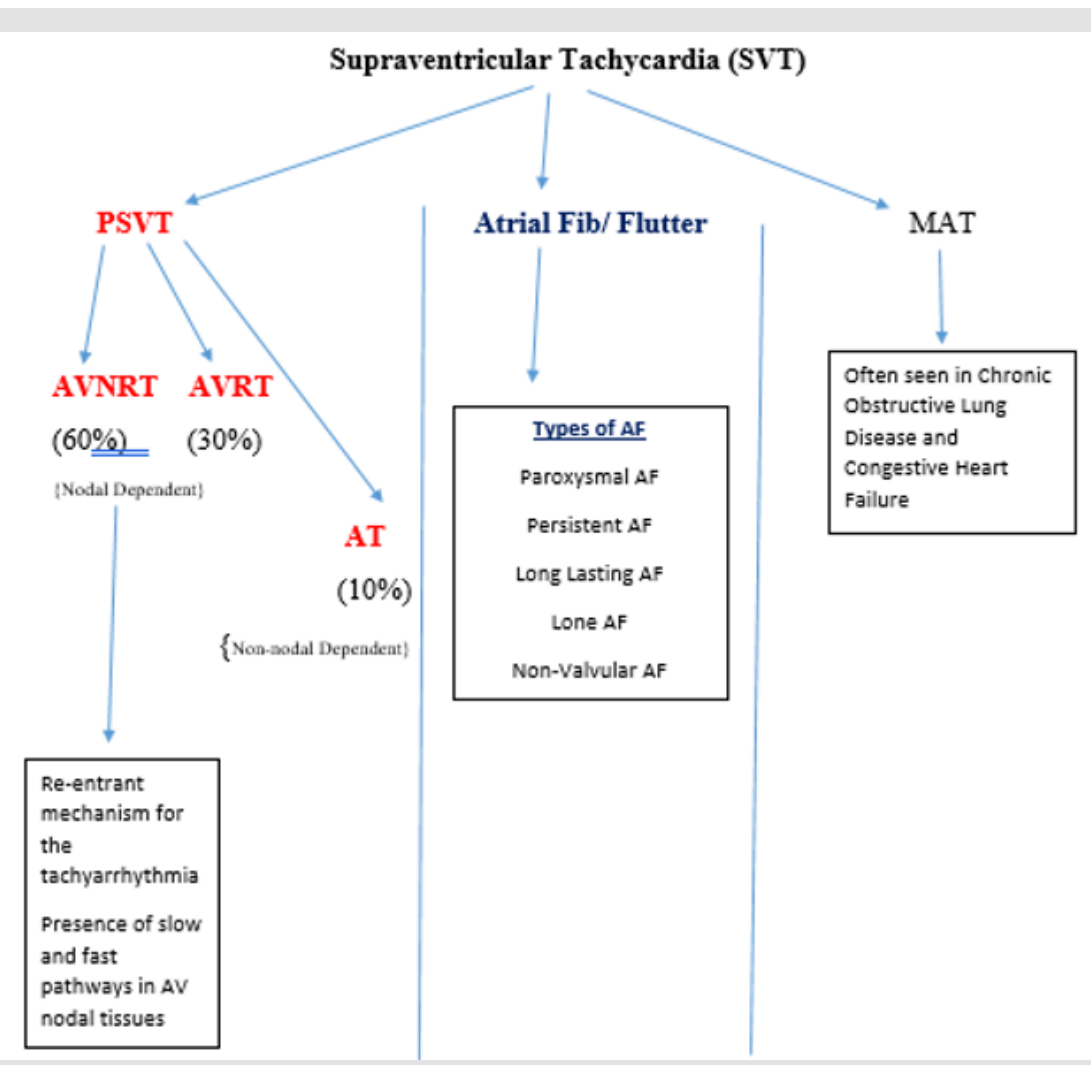

Figure 3: Classification of SVT [5-7].

\section{Mechanisms and Postulations: PSVT and AF}

There are currently some evidence as well as postulations that have been put forth in the literature to explain the phenomenon observed. Some of these are discussed below:

1. Currently it is noted that the atrioventricular accessory pathway (also known as the slow pathway) is involved in the genesis of AF. The phenomenon of enhanced atrial vulnerability can lead to the degeneration of AVNRT to AF. Here it is thought that during PSVT there is disturbance in the atrial electrophysiology, and this may be the mechanism of initiation of AF, when the slow pathway becomes activated $[8,9]$.

2. During PSVT there is increased atrial refractoriness and as a result of the mechano-electrical feedback paroxysmal AF can be initiated [9-11].

3. There is also a postulation that increased atrial dispersion from increased stretch during PSVT can induce AF. Increased size of the atrial has been correlated with enhanced tissue vulnerability and thus the predisposition to AF. The change in size and pressure of the atria during PSVT creates electrophysiologic changes which can generate AF [10-12].

4. There is also a suggestion that genetic polymorphism predisposes patients to both arrhythmias (i.e.. AVNRT and AF)
[12].

5. Some authors have reported that a significant proportion of patients coming for AF ablation are inducible for SVT. Alternatively, others have observed that SVT ablation in their patients showed a preventive effect on AF occurrences in patients with documentation of having both arrhythmias [5, 13-15].

6. Others have reported direct observations that synchronized tachyarrhythmias (atrial flutter, ANVRT, AVRT) can trigger AF $[15,16]$.

7. It is also thought that the transition from AVNRT to AF may begin in the pulmonary vein area. The pulmonary veins' myocardial sleeve, which is an extension of the left atrium, is thought to be potentially arrhythmogenic [17-19] The AF will continue if the reentrant wavelets continue roving through the atrial tissue. On the other hand, there have also been some postulates that there are non-pulmonary vein (NPV) triggers that may be responsible for persistent AF. The mechanism for this it appears may be due to the combination of reentrant and enhanced automaticity pathogenesis. Some have also gone on to observe that there is the left atrium NPV and right atrium NPV tissues and one may be more likely to be the causation of AF in each individual patient [20-24]. 


\section{Conclusion}

As there are multiple explanations and postulations for the possible link between PSVT and AF happening, as in the scenario we started with, it would be evident that the exact causation remains controversial and nebulous. The causation is likely to be multifactorial. In the meantime, as clinicians, it is good to be aware of this and deepen our understanding of why certain drugs are recommended for their therapy and management. It may shed some light on what mechanism/s are being targeted.

\section{References}

1. Colucci RA, Silver MJ, Shubrook J (2010) Common types of supraventricular tachycardia: Diagnosis and management. Am Fam Physician 82(8): 942-952.

2. Mark DG, Brady WJ, Pines JM (2009) Pre-excitation syndromes: diagnostic considerations in the ED. Am J Emerg Med 27(7): 878-888.

3. Ganz LI, Friedman PL (1995) Supraventricular tachycardia. N Engl J Med 332(3): 162-173.

4. Delacretaz E (2006) Clinical practice: supraventricular tachycardia. N Engl J Med 354(10): 1039-1051.

5. Frey MK, Richter B, Gwechenberger M, Marx M, Pezawas T, et al. (2019) High incidence of atrial fibrillation after successful catheter ablation of atrioventricular nodal reentrant tachycardia: 115.5 year follow up. Scientific Report. Nature Research 9: 11784.

6. Rosso R, Kistler P (2010) Focal atrial tachycardia. Heart 69: 181-185.

7. Ozcan C, Strom JB, Newell JB, Mansour MC, Ruskin JC (2014) Incidence and predictors of $\mathrm{AF}$ and its impact on long term survival in patients with supraventricular arrhythmias. Europace 16: 1508-1514.

8. Chen YJ, Chen SA, Tai CT, Wen ZC, Feng AN, et al. (1998) Role of atrial electrophysiology and autonomic nervous system in patients with SVT and paroxysmal AF. J Am Coll Cardiol 32: 732-738.

9. Coumel P (1992) Neural aspects of PAF. In: Falk RH, Podrid PJ eds. Atrial fibrillation: Mechanisms and management. New York, NY Raven Press 109-125.

10. Klein LS, Miles WM, Zips DP (1990) Effect of atrioventricular interval during pacing or reciprocating tachycardia on actual size and pressure and refractory period. Circulation 82: 60-68

\section{ISSN: 2574-1241}

DOI: 10.26717/BJSTR.2021.37.005982

Lateef Fatimah. Biomed J Sci \& Tech Res

This work is licensed under Creative

Commons Attribution 4.0 License

Submission Link: https://biomedres.us/submit-manuscript.php
11. Henry WL, Morganroth J, Pearlmen AS (1976) Relations between echocardiographically determined left atrial size and AF. Circulation 53: 273-279.

12. Hurwitz JL, German LD, Packer DL, Wharton JM, MCCarthy EA, et al. (1990) Occurrence of AF in patients with paroxysmal SVT due to AVNRT. Pacing Clin Electrophysiol 13(6): 705-710.

13. Sciarra L, Rebecchi M, De Ruvo E, De Luca L, Zuccaro LM, et al. (2010) How many AF ablation candidates have an underlying SVT previously unknown? Efficacy of isolated triggering arrhythmia ablation. Europace 12: $1707-1712$.

14. Sauer WH, Alonso C, Zado E, Cooper JM, Lin D, et al. (2006) AVNRT in patients referred for $\mathrm{AF}$ ablation. Response to ablation that incorporates slow pathway modification. Circulation 114: 191-195.

15. Katrisis DG, Giazitzoglou E, Wood MA, Shepard RK, Parvez B, et al. (2007) Inducible SVT in patients referred for catheter ablation of AF. Europace 9: 785-789.

16. Brugada J, Mont L, Matas M, Navarro-Lopez F (1997) AF induced by AVNRT. Am J Cardiol 80: 1609-1610.

17. Palma EC, Ferrick KJ, Gross JN, Kim SG, Fischer JD (2000) Transition from AVNRT to AF begins in the pulmonary veins. Circulation 102: 937.

18. Chen YJ, Chen SA (2006) Electrophysiology of pulmonary veins. J Cardiovasc Electrophysiol 17: 220-224.

19. Mahida S, Sacher F, Derval N, Berte B, Yamashita S, et al. (2015) Science linking pulmonary veins to atrial fibrillation. Arrhythm Electrophysiol $\operatorname{Rev} 4(1): 40-43$.

20. Saltz T, Waki K, Bcker AE (2000) Left atrium myocardial extension into pulmonary veins in humans: Observed relevance for atrial arrhythmia. J Cardiovasc Electrophysiol 4: 888-894.

21. Yamane T, Shah DC, Jais P (2002) Dilatation as a marker of pulmonary vein initiating AF. J Interv Card Electrophysiol 6: 245-249.

22. Chen YJ, ChenSA, Chen YC (2001) Effect of rapid atrial pacing in the arrhythmogenic activity of single crdiomyocyte from pulmonary vein: implication in initiating AF. Circulation 104: 2849-2854.

23. Santageli P, et al. (2016) Prevalence and distribution of focal triggers in persistent and long-standing AF. Heart Rhythm 13: 374-382.

24. Lee SH, et al. (2005) Predictors of non-pulmonary vein ectopic beats initiating paroxysmal AF. J Am Coll Cardiol 46:1054-1059.

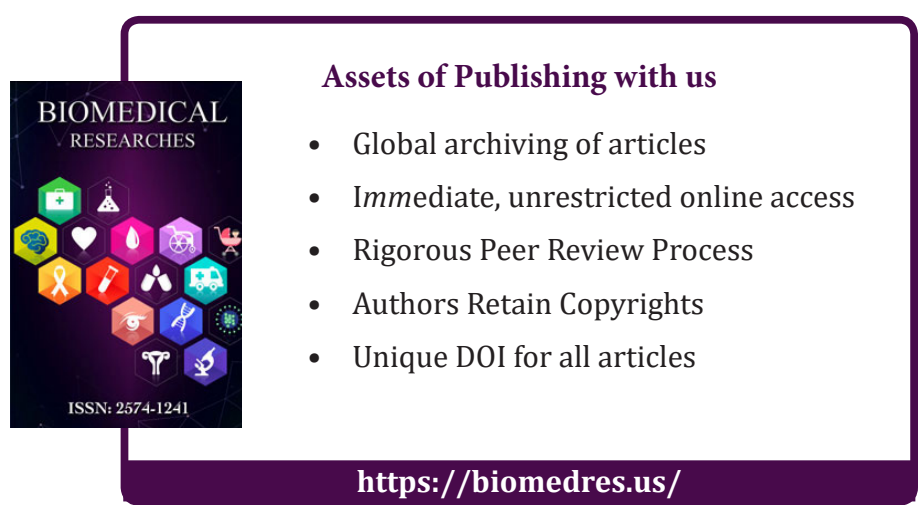

